\title{
Surgical Management of Maxillofacial Injuries in Iraq
}

\author{
Tahrir Nazzal Aldelaimi*
}

Assistant Professor, Department of Oral \& Maxillofacial Surgery, College of Dentistry, Anbar University, Iraq

\section{Abstract}

Background: One of the most demanding aspects of emergency medicine is the management of patients who have suffered facial trauma. Difficult circumstances such as the high number of casualties, severity of the facial wounds, coupled with the limited number of operating rooms and hospital beds, were a constant challenge to the surgeons

Aims of Study: This study discusses types of maxillofacial injuries and their surgical managements.

Materials \& methods: The following study focuses on maxillofacial injuries that were treated at Maxillofacial Unit, Ramadi Teaching Hospital and Department of Oral \& Maxillofacial Surgery, College of Dentistry, Anbar University, Iraq. Total of (518) cases were chosen on the basis of them being only oral and maxillofacial injuries including 325 males and 193 females with age range from 8 to 75 years old

Results \& conclusions: Most cases were in the age group (20-29) years, $312(60.2 \%)$ patients were injured with missile fragments, isolated soft tissue injuries were found in $56(10.8 \%)$ while, skeletal injuries were found in $462(89.2 \%)$,facial nerve injuries which found in $57(11 \%)$ patients, $119(40 \%)$ patients had mandibular fractures were treated conservatively and $179(60 \%)$ patients were treated by direct skeletal fixation.

Keywords: Maxillofacial trauma; War injuries; Missile;Soft tissue injuries; Skeletal injuries

\section{Introduction}

War continues to be the best school for surgeons. Historically, military conflicts had provided significant opportunities for the advancement of trauma surgery 1 . Banks 2 stated that missile injuries by their special nature have lessons applicable to the general understanding of facial trauma.

Maxillofacial region comprises a complex anatomical arrangement of bone and soft tissues. Contained within the face are systems that control specialized functions including seeing, hearing, smelling, breathing, eating, and talking. Also, the vital structures in the head and neck region are intimately associated. This complex anatomy makes missile injuries affecting this region one of the most complexand challenging problems facing surgeons. The importance of an oral and maxillofacial surgeon on the casualty team was proved in the Vietnam War when the medical care given to American soldiers in this war was outstanding [3-5]. The primary phase deals with survival of the patient by maintenance of hemodynamic and airway functions. In the intermediate phase, supportive care such as antibiotic prophylaxis and treatment of infection, control of bleeding, and tissue debridement are done. The third phase is the reconstructive phase [6-8]. Modern advances in military weapons have undoubtedly resulted in an ever increasing incidence of injuries in armed conflicts. However, the world's major wars have produced many advances in the management and treatment of wounds. The introduction of a wide range of potent antibiotics, improved anesthetic techniques and better postoperative care has all added to greatly increasing the survival rate of casualties. Anbar is the largest province in Iraq in surface area (more than 32\%), with a population of about 1.5 million, forms western borders. Iraq in general and Anbar in particular became the world's battlefield for terrorist attack to many civilians by different types of weapons including explosive cars, explosive belts, refile bullets and handgun bullets. Every conceivable type of weapon has been used, which has resulted in the full spectrum of violent injuries. The severity of injuries ranged from simple facial laceration and dentoalveolar fractures of the jaws to injuries that are incompatible with life.

\section{Patients and Methods}

During the period from May 2003 to December 2010, a total of
(518) cases were treated at Maxillofacial Unit, Ramadi Teaching Hospital, and Department of Oral \& Maxillofacial Surgery, College of Dentistry, Anbar University, Iraq. 325 Patients were males and 193 were females, their age range from 8 to 75 years old with a mean age of 41.2 years old. Of those these cases had sustained only maxillofacial injuries and were included in this study. Patients that came in with combined maxillofacial and other injuries were triaged appropriately and treated by other specialists according to priority, but were not included in this study.

According to Stump et al. [9] Wounds were classified into penetrating, perforating, and avulsive wounds. Missiles were divided into high velocity rifle bullets, low-velocity missiles (includes handgun bullets, airgun, and shotgun), and fragments. Injuries were divided into isolated soft tissue wounds and skeletal injuries, the later were further divided into mandibular fractures, mid-face fractures, and both mandibular and midface fractures. In emergency room, for all patients included in the study, a standardized case sheet form was made that includes: history, primary survey, life saving procedures, secondary survey, definitive treatment, intermediate phase, and rehabilitation. Patients in this study received immediate care According to ATLS approach to maintain or establish adequate airway, to monitor vital signs and to initiate an intravenous line. The facial structures of each patient were appropriately examined by radiograph and/or CT scan. Surgical priorities were then decided. All of the wounded received surgical treatment ranging from debridement and suturing to immediate reconstruction of facial structures. All surgeries were performed under general anesthesia through either intranasal or intraoral endotracheal tubes. Tracheostomies, whether emergency or elective, were made as indicated. Timing of primary surgery was decided according to many

*Corresponding author: Tahrir Nazzal Aldelaimi, Assistant Professor, Department of Oral \& Maxillofacial Surgery, College of Dentistry, Anbar University, Iraq, E-mail: tahrir_aldelaimi@yahoo.com

Received October 16, 2011; Accepted December 21, 2011; Published January 05, 2012

Citation: Aldelaimi TN (2012) Surgical Management of Maxillofacial Injuries in Iraq Dentistry 2:113. doi:10.4172/2161-1122.1000113

Copyright: (c) 2012 Aldelaimi TN. This is an open-access article distributed under the terms of the Creative Commons Attribution License, which permits unrestricted use, distribution, and reproduction in any medium, provided the original author and source are credited. 
factors including: the need of a lifesaving procedure, patient's general condition, past-medical history of the patient as well as the presence of associated injuries. Theater availability was a crucial factor in times of mass casualties. After considering all the previously mentioned factors, primary surgery was executed as early as possible to avoid infection. When patient conditions and circumstances allowed, definitive care of maxillofacial Injury was attempted at the initial surgery. All patients were placed on systemic antibiotic cover that consisted of Metronidazole 500mg $\times 3$ IV . And Cefotaxime $1 \mathrm{~g} \times 4 \mathrm{IV}$ were used; tetanus prophylaxis was not available always in our hospital (Figure $1,2,3,4,5$ and 6 ).

\section{Results}

Patient sample in this study composed of (518) patients, with age range from 8 to 75 years old; mean was 41.2 years old who were treated at Oral \& Maxillofacial Surgery Department, College of Dentistry, Anbar university and Maxillofacial unit at Ramadi Teaching Hospital,

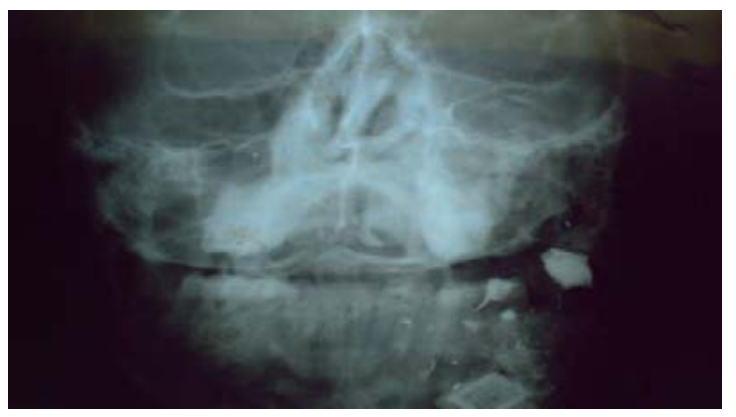

Figure 1: PA radiograph showing bone destruction and multiple missile fragments.

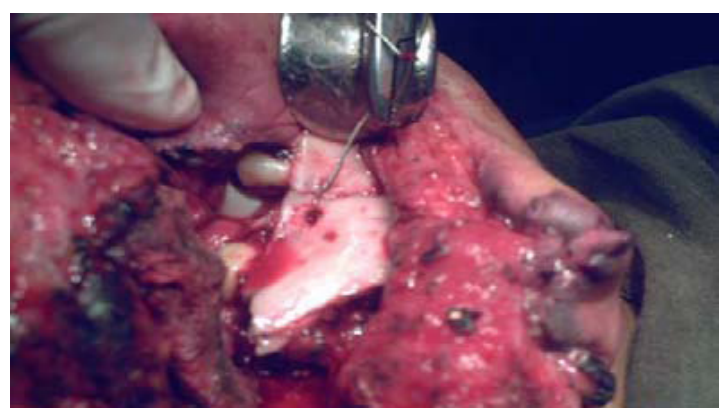

Figure 2: wound exploration and placing of direct transosseous wiring

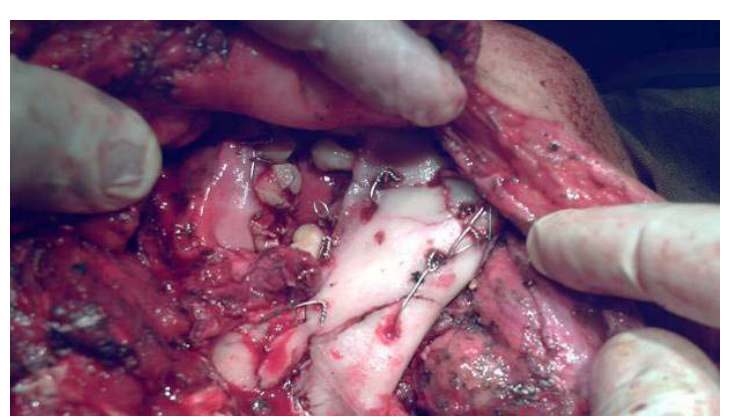

Figure 3: complete re-reduction and re-alignment of the mandible utilizing "direct transosseous wiring, lower border wiring, upper border wiring, upper and lower eyelet for IMF"

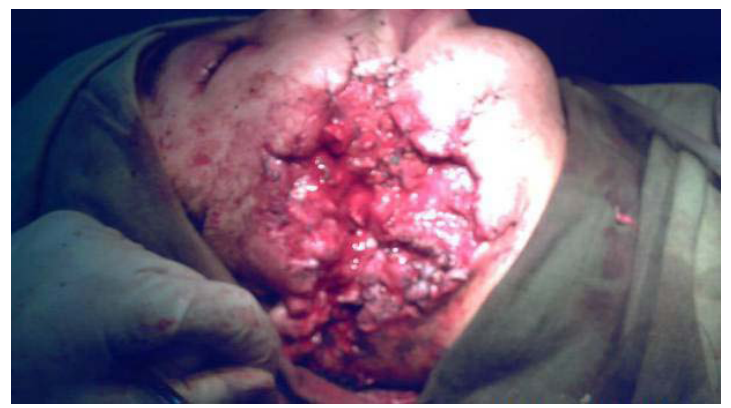

Figure 4: wound closing in layers

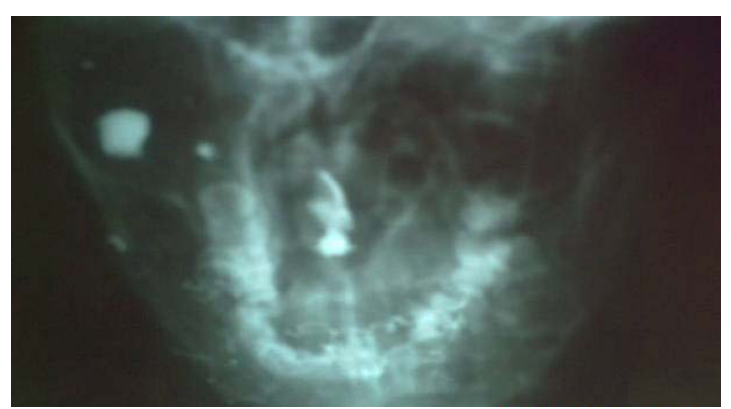

Figure 5: postoperative PA radiograph

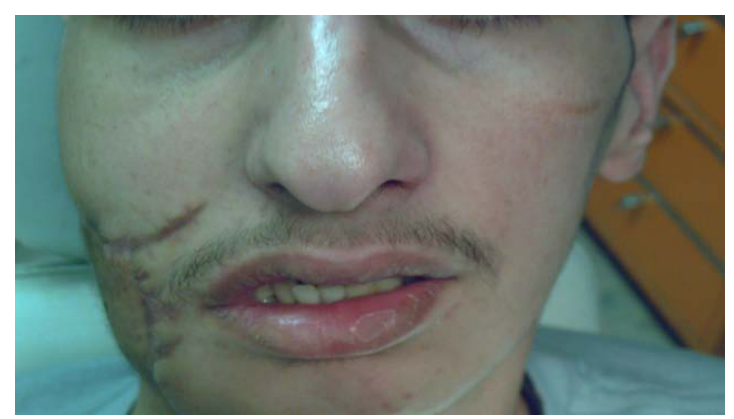

Figure 6: postoperative veiw

Anbar, Iraq, including 325 males and 193 females. Most cases were in the age group (20-29) years (Table 1). Regarding type of missile; 312 (60.2\%) patients were injured with missile fragments of explosive cars, explosive belts, mines, mortars, IED and grenades while patients were injured with bullets included 128 (24.7\%) rifle bullets, 61 (11.6\%) handgun bullets, and $16(3.1 \%)$ airgun pellets. According to site of injuries, isolated soft tissue injuries were found in 56 (10.8\%) while, skeletal injuries were found in $462(89.2 \%)$ of patients including that mandibular fractures were found in 298 (57.5\%) patients, while middle third fractures were found in $164(31.7 \%)$ patients. Regarding the need for airway management $56(10.8 \%)$ patients needed emergency tracheostomy under local anesthesia at emergency room and 17 (3.3\%) patients needed tracheostomy because of critical postoperative period due to edema of the series had tracheostomy eventually. Only $23(4.4 \%)$ patients were presented with active bleeding which would not stop without intervention including $6(1 \%)$ patients had injury to great vessels. Overall Mortality was $2 \%$. One of the mortalities was due to direct brain damage caused by the missile or due to complication involving CNS (brain abscess, meningitis). 


\begin{tabular}{|c|c|c|c|c|}
\hline \multicolumn{2}{|c|}{ Sex } & Male & Female & Total $\mathrm{n}(\%)$ \\
\hline \multirow{7}{*}{ Age group } & $0-9$ & 14 & 8 & $22(2 \%)$ \\
\hline & $10-19$ & 42 & 38 & $80(15.4 \%)$ \\
\hline & $20-29$ & 83 & 45 & $128(24.7 \%)$ \\
\hline & $30-39$ & 71 & 36 & $108(20.8 \%)$ \\
\hline & $40-49$ & 37 & 23 & $60(11.6 \%)$ \\
\hline & $50-59$ & 35 & 22 & $57(11 \%)$ \\
\hline & $60-69$ & 22 & 16 & $38(7.3 \%)$ \\
\hline \multirow{4}{*}{ Type of Missile } & Missile fragment & 189 & 123 & $312(60.2 \%)$ \\
\hline & Rifle bullets & 88 & 41 & $128(24.7 \%)$ \\
\hline & Handgun bullets & 36 & 25 & $61(11.6 \%)$ \\
\hline & Airgun pullets & 12 & 4 & $16(3.1 \%)$ \\
\hline \multirow{3}{*}{ Site of injury } & Soft tissues injury & 34 & 22 & $56(10.8 \%)$ \\
\hline & Mandible injury & 176 & 122 & $298(57.5 \%)$ \\
\hline & Middle third injury & 115 & 49 & $164(31.7 \%)$ \\
\hline \multirow{5}{*}{ Type of injury } & Facial nerve & 31 & 26 & $57(11 \%)$ \\
\hline & Eye globe & 16 & 9 & $24(4.6 \%)$ \\
\hline & CNS & 13 & 6 & $19(3.7 \%)$ \\
\hline & Neck & 7 & 4 & $11(2.1 \%)$ \\
\hline & Lachrymal & 4 & 1 & $5(0.9 \%)$ \\
\hline \multirow{3}{*}{$\begin{array}{l}\text { Soft tissue } \\
\text { treatment }\end{array}$} & Primary closure & 16 & 13 & $29(51 \%)$ \\
\hline & Local flaps & 11 & 5 & $16(28.6 \%)$ \\
\hline & lodoform packing & 7 & 4 & $11(19.6 \%)$ \\
\hline \multirow{2}{*}{$\begin{array}{c}\text { Mandibular } \\
\text { treatment }\end{array}$} & Close treatment & 55 & 64 & $119(40 \%)$ \\
\hline & Open treatment & 121 & 58 & $179(60 \%)$ \\
\hline \multirow{2}{*}{$\begin{array}{l}\text { Middle third } \\
\text { treatment }\end{array}$} & Close treatment & 41 & 23 & $64(40 \%)$ \\
\hline & Open treatment & 74 & 26 & $100(60 \%)$ \\
\hline
\end{tabular}

Table 1: patients characteristics

Diagnostic workup included conventional radiograph (posterioanterior view, occipitomental view, lateral oblique) and/or CT scan for all patients. In 18 (3.5\%) patients CT scan was ordered to exclude intracranial injury and $25(4.8 \%)$ patients CT scan was ordered to evaluate orbital skeleton, while in 13 (2.5\%) patients CT scan was ordered for better localization of retained missiles.

The most commonly found injury of structures of maxillofacial region was facial nerve injuries which found in $57(11 \%)$ patients and ophthalmic injury was found in $24(4.6 \%)$ patients while $11(2.1 \%)$ patients had injuries to the neck (vascular, laryngotracheal, and neurogenic) and 19 (3.7\%) patients had injury to the CNS and 5 (0.9\%) patients had injuries to the lachrymal system.

Regarding treatment; In this study 56 patients had extensive lacerations and injuries of soft tissues as part of perforating and avulsive wounds that treated by primary closure where suturing was done after undermining in 29b (51.8\%) patients and local advancement, transposition, and rotation flaps was used for immediate reconstruction in $16(28.6 \%)$ patients with mild to moderate soft tissue loss while 11 (19.6\%) patients presented extensive soft tissue loss and was packed with Iodoform pack.

Regarding treatment of 298 patients of mandibular fractures; 119 (40\%) were treated conservatively due to reasons including unstable general condition utilizing arch bar, or eyelet wiring as indicated, while 179 (60\%) patients were treated by direct skeletal fixation included; transsosseus wiring in $122(41 \%)$ patients, miniplates in $28(9.4 \%)$ patients, reconstruction plate in $11(3.7 \%)$ patient and intramedullary K wire in $18(6 \%)$ patients. Furthermore; The treatment of (164) patients found to have midface fractures, $64(40 \%)$ patients had conservative treatment and $100(60 \%)$ required active treatment including 14 (8.5\%) patients had localized fragmentation of the maxillary alveolus with loss of multiple teeth that required suturing only and 8 (4.9\%) patients were treated by packing maxillary sinus with antrostomy for supporting comminuted orbital floor fractures, $59(36 \%)$ patients were treated by suspension wires with IMF, 19 (11.6\%) patients were treated using multiple transosseus wires approached through lacerations caused by the missile.

\section{Discussion}

Peter Banks [2] stated that bullet wounds are a feature of terrorist and guerilla war while fragment injury from bomb explosions is the hallmark of conventional war and terrorist attacks. The distribution of types of missiles in the current study reflects the bizarre nature of the conflict taking place. Iraq has become the field of the third world war of terrorists for the last two years and the war is a combination of conventional war, civil unrest, crimes, and terrorism. The severity of these injuries depends on the type of missile site of injuries and the amount of soft tissue loss and bone destroyed. Classification of injuries is a useful procedure for the clinicians to communicate with each other by using a brief terminology rather than lengthy descriptions of injuries sustained. Classification should adequately describe the site, extent and nature of the hard and soft tissue injuries.

In high-velocity missile injury, large amounts of energy are transferred to the tissues of the body and result in massive injury to soft tissue and ablation of cortical bone. Airway disruption is significantly more likely after a high-velocity injury this demonstrated in the current study where high percent of patients who needed airway management where injured by high velocity missile.

Blast injury survivors usually experience multiple injuries that are characterized by gross contamination. Our results confirm the importance of the secondary blast injury that sends objects flying through the air as well as imparting high velocity to the resulting fragments as the main wounding agent in survivors and the importance of looking for these injuries and cast a light on the changing trend in injuries caused by missiles characterized by the emerging incidence of multiple hits to multiple body regions in survivors. The first 24 hours from the time of injury is the most suitable time for primary closure and after that all wounds should be packed open. However, favorable blood supply to the face coupled with the fact that in the face the whole of the wound tract in most of the cases is available for surgical excision allowed primary closure of extensive lacerations in this study. Early operative repair of mandibular fractures and the reconstitution of the soft tissue position are critical in obtaining optimal aesthetic and functional results and it is important that the remaining segments of the mandible be held in an anatomic position throughout the period of soft tissue and bone reconstruction to limit the magnitude of the deformity therefore active treatment was undertaken for mandibular fractures cases including a closed reduction and indirect fixation was done in the treatment of comminuted fractures.

\section{References}

1. Kummoona R (2008) Posttraumatic missile injuries of the orofacial region. $J$ CraniofacSurg 19: 300-305

2. Banks P, Mellor S, Haywood IR (1994) Gunshot wounds. In: Williams JLT ed. Rowe and Williams Maxillofacial Injuries, 2nd ed, Churchill Livingstone, London, England.

3. Jacob E, Setterstrom JA (1989) Infection in war wounds: experience in recent military conflicts and future considerations. Mil Med 154: 311-315

4. Maughon JS (1970) An inquiry into the nature of wounds resulting in killed in action in Vietnam. Mil Med 135: 8-13.

5. Hardaway RM 3rd (1978) Viet Nam wound analysis. J Trauma 18: 635-643. 
6. Osborne THE (1991) Bays RA: Pathophysiology and management of gunshot wounds to the face, in FonsecaRJ, Walker RV: Oral and Maxillofacial Trauma. Philadelphia, PA, USA, PP: 672.

7. Nelson TJ, Wall DB, Stedje-Larsen ET, Clark RT, Chambers LW, et al. (2006) Predictors of mortality in close proximity blast injuries during Operation Iraqi Freedom. J Am CollSurg 202: 418-422.
8. Kummoona R, Muna AM (2006) Evaluation of immediate phase of management of missile injuries affecting maxillofacial region in iraq. J CraniofacSurg 17: 217 223

9. Stump TE (1983) Maxillofacial injuries from high velocity missiles: Mechanism wounding action, and classification of gunshot wounds. In: Jacobs JR, ed Maxillofacial Trauma. New York. 